REVISTA X, Curitiba, volume 14, n.3,p. 33-49, 2019.

\title{
TRADUÇÃO DE HQ: O ESTUDO DE UMA TIRA DE CALVIN E HAROLDO EM TRÊS LÍNGUAS
}

Comics Translation: An Study Of Calvin \& Hobbes Comic Strip In Three Languages

\author{
Rosa YOKOTA (UFSCar/USP) ${ }^{1}$ \\ Jéssica Rodrigues ROSA (UFSCar) ${ }^{2}$
}

\begin{abstract}
RESUMO: Neste artigo, apresentamos algumas reflexões sobre a tradução de HQs a partir da análise da tradução de uma tira dos personagens Calvin e Haroldo, de Bill Watterson. A tira original está em inglês e as traduções, em espanhol e português. Apesar de considerar as Modalidades de Tradução, de Aubert (1998), que focalizam o produto linguístico, aborda-se o texto como junção do desenho com o material linguístico, o contexto de circulação das traduções e os efeitos de sentido produzidos pelos elementos não verbais. Serão destacados: um aspecto sintático, o sujeito oracional, e as mudanças de sentido presentes nos textos traduzidos.
\end{abstract}

PALAVRAS-CHAVE: Tradução; História em Quadrinhos; Sujeito; Português; Sintaxe.

ABSTRACT:In this article, we draw some reflections on the comics translation from the analysis of a Calvin and Hobbes comic strip, by Bill Watterson. The original comic strip is in English and the translations are in Spanish and Portuguese. Although considering the Aubert's translation modalities (1998), which focus on the linguistic product, the text is addressed as a combination of the cartoon with the linguistic material, the context of the translation circulation and the meaning effects produced by the non-verbal elements. A syntactic aspect, the sentence subject, and the shift in meaning, present in the translated texts, will be highlighted.

KEYWORDS: Translation; Comics, Subject; Portuguese; Sintax

\section{INTRODUÇÃO}

Neste artigo, analisa-se a tradução de uma das tiras da história em quadrinhos (HQ) dos personagens Calvin e Haroldo (Calvin \& Hobbes), do cartunista norteamericano Bill Watterson. A partir da versão original em inglês e das traduções ao espanhol e ao português que circulam através de sites, jornais e livros, serão abordadas as diferentes possibilidades dadas pelos tradutores a um item específico, o sujeito oracional, em uma das tiras dos personagens citados. Mesmo levando em consideração

\footnotetext{
${ }^{1}$ Docente do Departamento de Letras e do Programa de Pós-Graduação em Linguística da Universidade Federal de São Carlos. Pesquisadora Colaboradora da Universidade de São Paulo.Email: rosayokota@yahoo.com

${ }^{2}$ Mestranda no Programa de Pós-Graduação em Linguística da Universidade Federal de São Carlos, bolsista Fapesp processo 2017/09732-5.Email: jessrrosa@ gmail.com
} 
REVISTA X, Curitiba, volume 14, n.3,p. 33-49, 2019.

que a HQ é um texto multimodal que envolve um tratamento que deve ir além da operação estritamente linguística (ASSIS, 2016), o interesse despertado por esta tira se deve aos diferentes sentidos que as traduções ao português e ao espanhol tomaram, diferenciando-se ou aproximando-se do original de acordo com a opção do tradutor e as possibilidades sintáticas de cada língua.

Apesar de considerar em nossa análise as modalidades de tradução propostas por Aubert (1998), que envolvem aspectos mais relacionados com o produto linguístico, tem-se a consciência da importância de considerar o texto como junção do desenho com o material linguístico, o contexto de circulação das traduções e os efeitos de sentido produzidos pelos elementos não verbais.

O aspecto linguístico que será destacado é a presença ou não do sujeito oracional através de demonstrativo neutro, pronome pessoal tônico ou categoria vazia ([Ø]) e as interpretações dadas pelas traduções que circulam em jornais e outros meios.

Além de ser um material que fascina os leitores, o fato das HQs serem usadas como material didático em aulas de línguas estrangeiras despertou o nosso interesse por este que é considerado por Mendonça (2010) um gênero textual que merece ser abordado e estudado pelos estudos acadêmicos. Esperamos contribuir para a reflexão sobre dois aspectos que se destacaram ao escolhermos a tira, objeto de análise deste artigo: (1) as peculiaridades da sintaxe, em especial o preenchimento do lugar argumental de sujeito oracional e (2) o uso de HQs no desenvolvimento de atividades que favoreçam o ensino de tradução e a pesquisa tradutológica.

Neste artigo, são apresentados inicialmente, de forma breve, alguns aspectos sobre a tradução de HQs e uma síntese sobre as tiras de Calvin e Haroldo, depois são comentadas as modalidades de tradução de acordo com Aubert (1998) e faz-se um recorte dos 13 pontos abordados pelo autor, em que se detalham aqueles que são relevantes para a análise da tira escolhida ${ }^{3}$, reproduzida a seguir:

\footnotetext{
3 A tira, de 1987, está na coletânea Yukon, ho! A Calvin and Hobbes Collection, de Bill Watterson, publicada pela Universal Press Syndicate, em 1989. Apesar de termos conhecimento dos livros em a tira foi publicada em inglês e português, tivemos acesso à tira somente através de sites da internet.
} 
Figura 1 - Tira de Calvin \& Hobbes em inglês
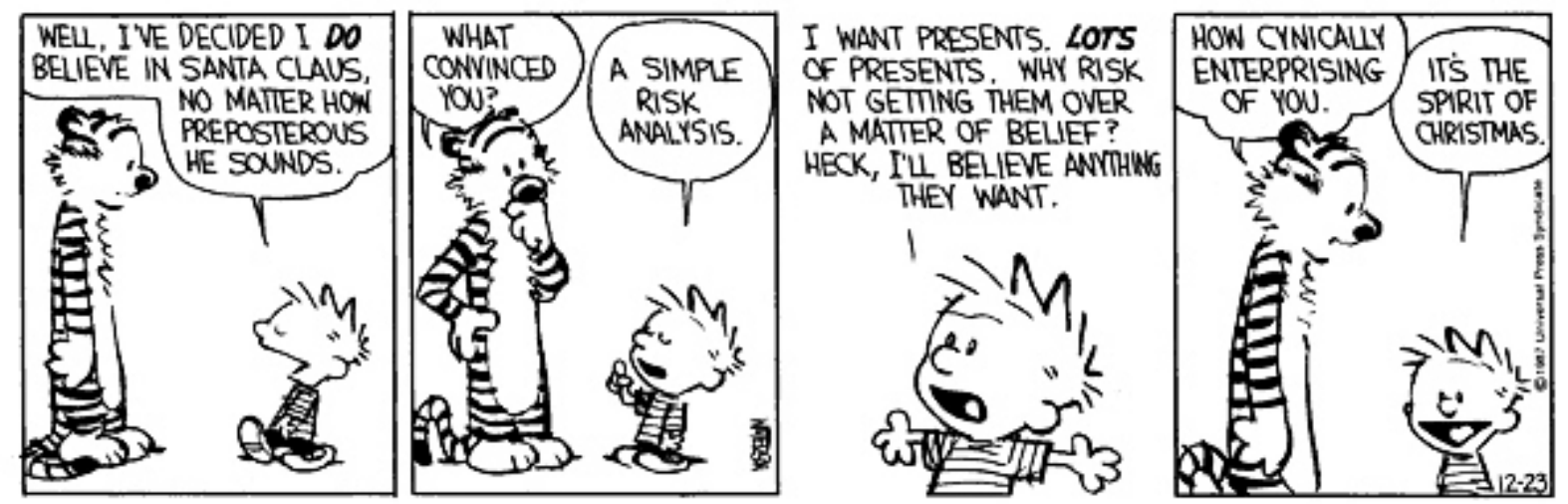

Extraído de: https://www.buzzfeed.com/ariannarebolini/christmas-lessons-from-calvin-andhobbes?utm term=.hegBBrmrE2\#.ptWOOMIMey Acesso em: 14 abr. 2017.

\section{A TRADUÇÃO DE HQS}

As HQs são consideradas como um dos veículos da "arte sequencial" (EISNER, 2001, p. 7) e como produto da cultura jornalística. Não há consenso quanto a sua origem. Há autores que apontam que elas surgiram na Inglaterra, no início da Revolução Industrial, no século XVIII. McCloud (1993) afirma que o pai do quadrinho moderno é Rodolphe Töpffer, que publicou a primeira HQ em meados de 1800, na Alemanha. Porém, há certa tendência a considerar que os quadrinhos surgiram no final do século XIX nos Estados Unidos, relacionados à expansão dos meios de comunicação em massa e ao aumento do número de leitores da mídia impressa ${ }^{4}$.

A tradução de HQ possui especificidades que passaram a ser objeto de pesquisa há pouco tempo. A HQ ganhou espaço nos meios de comunicação de massa durante o século $\mathrm{XX}$, o que fez com que passasse a ser traduzida amplamente para diferentes línguas. Apesar disso, sua inclusão na Encyclopedia of Translation Studies aconteceu somente em 2009, de acordo com Silva (2015), através do verbete Comics, de Federico Zanettin.

Nos dias atuais, em especial pelo sucesso das chamadas graphics novels, o interesse pelas HQs aumentou e elas chegam a ser comparadas à literatura, ou seja, ganharam o status de produto cultural prestigiado e objeto de estudo. Sua tradução,

\footnotetext{
${ }^{4}$ De acordo com Mendonça (2010, p. 210): "Ianonne e Ianonne (1994) admitem que, embora se possa encontrar rudimentos das HQs na arte pré-histórica, os precursores desse gênero, tal como o conhecemos hoje, surgiram apenas na Europa, em meados do século XIX, com as histórias de Busch e de Topffer. Os autores salientam que, no fim do século XIX, com o Menino Amarelo (Yellow Kid), desenhado por Richard Outcault e publicado semanalmente no jornal New York World, nascia o primeiro herói dos quadrinhos."
} 
REVISTA X, Curitiba, volume 14, n.3,p. 33-49, 2019.

portanto, passou a despertar interesse tanto do mercado editorial quanto do meio acadêmico, como observa Assis (2016).

Entretanto, a situação das HQs durante muito tempo foi de material para as massas; eram produtos baratos, descartáveis e destinados para o público infantojuvenil $^{5}$. Seu valor como produto cultural e científico era baixo, apesar de atingir um grande número de leitores por meio de jornais, revistas semanais e gibis.

A tira analisada neste artigo é considerada parte de uma obra prima das HQs. Apesar de ter ganhado prestígio e ter suas aventuras reunidas em livros editados cuidadosamente, os personagens Calvin e Haroldo pertencem à fase em que as HQs ainda eram consideradas como produto de comunicação de massa. Seu sucesso levou os personagens a terem suas peripécias publicadas em jornais de diferentes países; as tiras foram traduzidas a diferentes línguas, mas nem sempre houve a preocupação quanto à qualidade das traduções, como, por exemplo, o caso que este estudo pretende analisar. Pudemos verificar ao comparar o original em inglês e as traduções ao espanhol e ao português que há diferenças que alteram o conteúdo da fala de um dos personagens e, para este artigo nos limitamos a analisar um fato gramatical que diferencia as 1 .

\section{CALVIN E HAROLDO}

A primeira tira da série Calvin e Haroldo (Calvin \& Hobbes) do norte-americano Bill Wattersonfoi publicada em jornais norte-americanos em 18 de novembro de $1985^{6}$ e a última, em 31 de dezembro de 1995. Mesmo sem tiras novas, as republicações continuam até hoje em jornais de todo o mundo ${ }^{7}$ e também em coletâneas organizadas em livros.

A tradução de Calvin and Hobbes para o português, no Brasil, é 'Calvin e Haroldo'. Em Portugal, os nomes dos personagens foram mantidos. A tradução dos nomes dos personagens é um dado importante uma vez que a versão brasileira perde a intenção do autor de fazer referência a dois filósofos em sua HQ. Calvin foi inspirado no reformador religioso francês do século XVI, João Calvino, um dos fundadores do

\footnotetext{
${ }^{5}$ As tiras de jornal não são especificamente para o público infanto-juvenil, assim como as revistas em quadrinhos. Somente parte das HQs é destinada a este público, porém, no senso comum, durante muito tempo, as HQs foram consideradas leituras pouco sérias, tanto que eram proibidas em ambiente escolar (VERGUEIRO, 2006).

${ }^{6}$ No Brasil, o jornal O Estado de São Paulo (Estadão) publicou Calvin e Haroldo pela primeira vez em 15 de agosto de 1986, naquele momento, a tira recebeu o nome de somente um dos personagens, Calvin.

${ }^{7}$ Mais de 2000 jornais publicam ou publicaram as tiras. Informação extraída de: https://pt.wikipedia.org/wiki/Calvin_and_Hobbes. Consulta em: 15 abr. 2017.
} 
REVISTA X, Curitiba, volume 14, n.3,p. 33-49, 2019.

cristianismo protestante. A origem do nome de Hobbes, traduzido como Haroldo, foi Thomas Hobbes, filósofo inglês do século XVII ${ }^{8}$. A tradução portuguesa manteve os nomes, talvez por respeito às referências culturais dos mesmos.

As histórias de Calvin e Haroldo giram em torno da vida de um menino de 6 anos, Calvin, e seu tigre de pelúcia, Haroldo. As relações do menino com sua família (pai e mãe), babá, vizinha, escola e a vida no subúrbio norte-americano são retratadas nas tiras, assim como o mundo imaginário do personagem, em que seu tigre ganha vida e é seu companheiro de viagens interplanetárias, de jogos com um sósia, de lutas contra monstros, etc. A relação entre a criança e seu amigo imaginário cria situações caricatas, cômicas, críticas e comoventes.

\section{MODALIDADES DA TRADUÇÃO DE AUBERT}

Aubert (1998) apresenta a necessidade dos estudos tradutológicos teorizarem sobre questões estritamente linguísticas, mesmo reconhecendo a importância das vertentes que focalizam com maior intensidade: questões culturais, ideológicas e psicossociais das condições da produção do discurso; a teoria da leitura; o receptor enquanto coautor e outras contribuições. Sua perspectiva defende que é preciso haver uma abordagem técnica que explore questões pontuais da descrição linguística em situação de complementação e não de oposição a outras vertentes dos estudos da tradução.

Assim, o autor retoma os "procedimentos técnicos de tradução" propostos por Vinay e Darbelnet (1958 apud AUBERT, 1998). Eles organizaram procedimentos que faziam com que o texto traduzido (texto meta) fosse classificado como mais próximo até mais distante do texto fonte ou texto original. A reformulação do modelo de procedimentos resultou na proposta de "modalidades de tradução" para avaliar o produto da tradução qualitativa e quantitativamente.

Após pesquisas, no final dos anos 90, Aubert chegou a 13 pontos para estabelecer uma escala de diferenciação representada pelas modalidades de tradução. A

\footnotetext{
${ }^{8}$ Os nomes dos personagens teriam sido escolhidos como uma brincadeira de Bill Watterson para as pessoas que estudam ciências políticas e filosofia. João Calvino tinha discorrido sobre a depravação humana e a sua tendência a promover o mal. Thomas Hobbes foi autor da máxima 'O homem é o lobo do homem', ou seja, o homem é o predador do seu semelhante. O cartunista, cuja formação acadêmica foi em ciências sociais, acreditava que poucas pessoas perceberiam a razão da escolha dos nomes.
} 
seguir, será apresentado, brevemente, um recorte dos pontos, que foram limitados a $8^{9}$, seguindo os procedimentos da pesquisa de Silva (2015) para analisar HQs a partir da teoria de Aubert (1998). Para complementá-los, são inseridos alguns exemplos referentes a HQs compilados de Silva (2015) e adaptações que esta pesquisadora fez ao analisar as traduções da HQ argentina Mafalda ao português ${ }^{10}$. O recorte apresenta somente as modalidades que serão importantes para a análise da tira de Calvin e Haroldo escolhida para este artigo ${ }^{11}$.

A. Omissão - ocorre quando um dado segmento do texto fonte não é recuperado no texto meta. Pode ocorrer por diferentes razões, desde a censura até a falta de espaço, passando pela interpretação do tradutor, que considerou o segmento irrelevante. Silva (2015, p. 102) identifica a omissão de interjeição 'Dios mío...' na tradução de uma tira de Mafalda ao português.

B. Empréstimo - é um fragmento textual do texto fonte que é reproduzido no texto meta. O nome dos personagens pode ser traduzido ou, se forem mantidos, seria uma forma de empréstimo.

C. Tradução literal - é a tradução palavra por palavra, que apresenta correspondência em (1) número de palavras, (2) ordem sintática, (3) categorias lexicais e (4) opções lexicais. A seguir, o exemplo apresentado por Silva (2015, p. 106): ‘.. y que nunca seamos el jamón del sándwich internacional' / '... e que nunca sejamos o presunto do sanduiche internacional'. Silva (2015) distingue ainda 'Tradução literal próxima' de 'Tradução literal distante' de acordo com a similitude ortográfica das palavras utilizadas.

D. Transposição - quando um dos três primeiros critérios da tradução literal não pode ser cumprido, há transposição. Ou seja, quando há rearranjos morfossintáticos, desdobramentos lexicais, mudança de ordem de palavras, etc. Por exemplo: ¿¿Te parece? / Você acha?'. Há transposições obrigatórias e outras facultativas, de acordo com as características estruturais das línguas fonte e meta. Por exemplo, no caso do espanhol, o verbo transitivo 'mirar' pode ser traduzido como 'olhar', porém, o

9 Dos 13 pontos da proposta de Aubert (1998), foram omitidos: transcrição; decalque; explicitação/implicitação, adaptação e adaptação intersemiótica.

${ }^{10}$ A tabela 5 - Descrição das modalidades de tradução utilizadas na pesquisa, de Silva (2015, p. 126 -129) sintetiza as modalidades mobilizadas pela autora e as adaptações feitas.

${ }^{11}$ Para não repetir as informações que estão na análise, preferimos utilizar os exemplos de Silva (2015) em lugar de insertar diretamente as falas da tira que analisamos. 
REVISTA X, Curitiba, volume 14, n.3,p. 33-49, 2019.

complemento direto preposicionado do espanhol 'mirar a la humanidad', no português seria 'olhar a humanidade' (SILVA, 2015, p.119).

E. Modulação - um determinado segmento textual foi traduzido deslocando significativamente sua estrutura semântica de superfície, porém retendo o mesmo efeito geral de sentido no contexto correspondente. Por exemplo: 'It's very difficult / Não é nada fácil'. Ou, no caso do espanhol para o português: '¿Y a usted qué le importa? / E você o que tem com isso?'. Para Silva (2015), haveria a divisão entre Modulação facultativa (em que o tradutor teria a possibilidade de traduzir os significados de superfície nas modalidades de tradução literal ou transposição sem produzir erro de tradução) e Modulação obrigatória (o tradutor não teria como traduzir os significados de superfície nas modalidades literal ou transposição).

F. Erro - esta modalidade, segundo Aubert (1998, p. 109) não é uma solução tradutória, mas aquilo que nós entendemos realmente como erro no sentido comum. É o caso, por exemplo, da palavra 'a gente', no português, grafada como 'agente' em uma das traduções das tiras de Mafalda. Problemas causados por interferência lexical (falsos cognatos) e interferência sintática (estruturas agramaticais ou não correspondentes situacionalmente) são considerados erros evidentes por Silva (2015).

G. Correção - neste caso, trata-se de um problema no texto fonte que o texto meta não repetirá. São adequações feitas pelo tradutor para melhorar o texto final em relação ao texto fonte.

H. Acréscimo - é um segmento textual acrescentado pelo tradutor por conta própria, não motivado pelo conteúdo explícito ou implícito do texto original. Silva (2015: 114) exemplifica esta modalidade com uma tira em que Miguelito conta a seu amigo que quer ter 'una cadena de supermercados' quando crescer. A tradução ao português foi 'rede de supermercados gigantescos', ou seja, houve o acréscimo deum adjetivo.

Procurou-se, também, recuperar algumas características próprias das HQs que, durante a tradução, podem ser alteradas e afastar o texto fonte do texto meta, gerando perdas ou acréscimos de sentido.

\section{UMA TIRA E SUAS TRADUÇÕES: ANÁLISE DE CALVIN E HAROLDO}

Inicialmente, será feita uma análise de aspectos visuais e estruturais da tira, para que depois os aspectos linguísticos sejam focalizados.

$\mathrm{Na}$ tira original (fig. 1), são observadas algumas particularidades gráficas que 
REVISTA X, Curitiba, volume 14, n.3,p. 33-49, 2019.

não foram mantidas em todas as traduções consultadas. Uma delas é quanto à montagem da tira, que originalmente é uma sequência de quatro vinhetas que devem ser lidas da esquerda para a direita. Os balões de diálogo também devem ser lidos da esquerda para a direita, sendo que, na terceira vinheta, o balão não tem contorno e a fala de Calvin que aparece 'livre' é justamente a fala em que ele revela seu desejo íntimo, ou seja, a fala com menos controle racional e social.

A letra utilizada nos diálogos é a do próprio autor, ele utiliza letra bastão maiúscula e marca a ênfase com negrito em duas das vinhetas, a primeira e a terceira.

Figura 2 - Tira de Calvin y Hobbes em espanhol

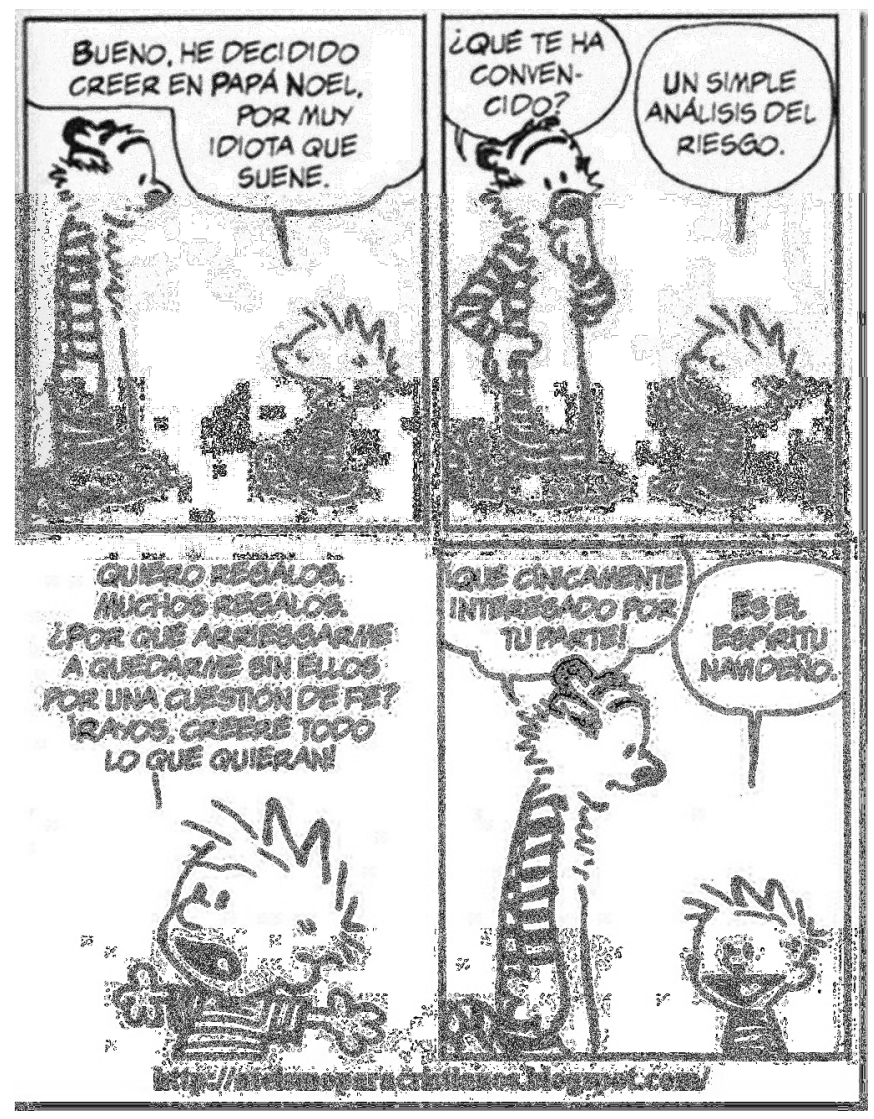

Fonte: extraído de http://ateismoparacristianos.blogspot.com/search?q=calvin. Acesso em: 20 abr. 2017.

A tira original (fig.1) foi traduzida para o espanhol (fig.2) ${ }^{12}$ e a versão que foi consultada tem formato diferente. Em lugar da tira cujas vinhetas se organizam da esquerda para a direta como normalmente é publicada em jornais, houve sua interrupção na segunda vinheta, a terceira e a quarta vinhetas passaram para a posição inferior e a

\footnotetext{
${ }^{12}$ Não foi possível localizar outras traduções de Calvin \& Hobbes ao espanhol.
} 
REVISTA X, Curitiba, volume 14, n.3,p. 33-49, 2019.

história ganhou o formato 'retrato'. A leitura passou a ser da esquerda para a direita, de cima para baixo.

A popularidade de determinadas HQs junto aos leitores fez com que editores e autores mudassem a montagem original, rediagramassem e reagrupassem as tiras para publicação em álbuns ou revistas. As tiras das figuras 2 e 3 são bons exemplos de como a mudança de suporte gráfico levou à mudança no formato das tiras.

Em espanhol a HQ foi chamada de "Calvin y Hobbes", ou seja, não houve mudança no nome dos personagens, mas se traduziu o conector 'and' (\&) por ' $y$ '. Assim, percebe-se o cuidado com os nomes dos personagens ao se fazer o empréstimo dos nomes próprios originais, algo raro na tradição espanhola, em que os tradutores castelhanizam os nomes estrangeiros ${ }^{13}$.

Apesar de manter as características dos balões de diálogo, as palavras em negrito não foram mantidas. Como todas as letras estão em maiúscula, o negrito foi reservado para marcar o início de oração (Quiero regalos. Muchos regalos) e o nome próprio (Papá Noel). Assim, percebe-se que as características gráficas da tira original não estão totalmente preservadas na tradução ao espanhol.

Em português, no Brasil, foram identificadas três traduções diferentes, porém, possivelmente há outras. Anteriormente, ao introduzir algumas informações sobre a tira, comentou-se a opção brasileira para o nome dos personagens: ao fazerem a adaptação os tradutores perderam a informação sobre Hobbes/Haroldo. Além disso, durante muito tempo, houve a omissão de Haroldo no título da tira nos jornais. Inicialmente o nome da tira era somente 'Calvin', depois passou a ser 'O melhor de Calvin' e posteriormente, 'O melhor de Calvin e Haroldo'.

Uma das traduções (fig. 3) apresenta o mesmo formato da tradução para o espanhol. Entretanto o uso de negrito pretende reproduzir a tira original.

Assim, apesar da mudança no formato, houve o cuidado de manter outros aspectos gráficos (balão e letra).

\footnotetext{
${ }^{13}$ Apesar de haver a possibilidade de manter o nome próprio na língua de origem, há vários exemplos de traduções de nomes de personagens de cultura em massa ao espanhol, por exemplo: "Você sabe quem é Bruno Díaz? Provavelmente sim, mas se não passou a infância assistindo desenhos animados em algum país hispânico, não saberá que se trata de Bruce Wayne, o Batman." (http://bujestraducoes.com.br/index.php/2018/09/01/traduzir-ou-nao-traduzir-nomes-proprios/ Consulta em: 10 mar. 2019). O mesmo ocorre com outros vários personagens de desenhos animados e HQs. Personalidades, como reis e rainhas tem seus nomes, na Espanha, castelhanizados pela imprensa (jornais e revistas, principalmente, de fofocas), por exemplo: Charles $=$ Carlos, Willian $=$ Guillermo.
} 
REVISTA X, Curitiba, volume 14, n.3,p. 33-49, 2019.

Figura 3 - Tira de Calvin e Haroldo em português ${ }^{14}$ em formato 'retrato'

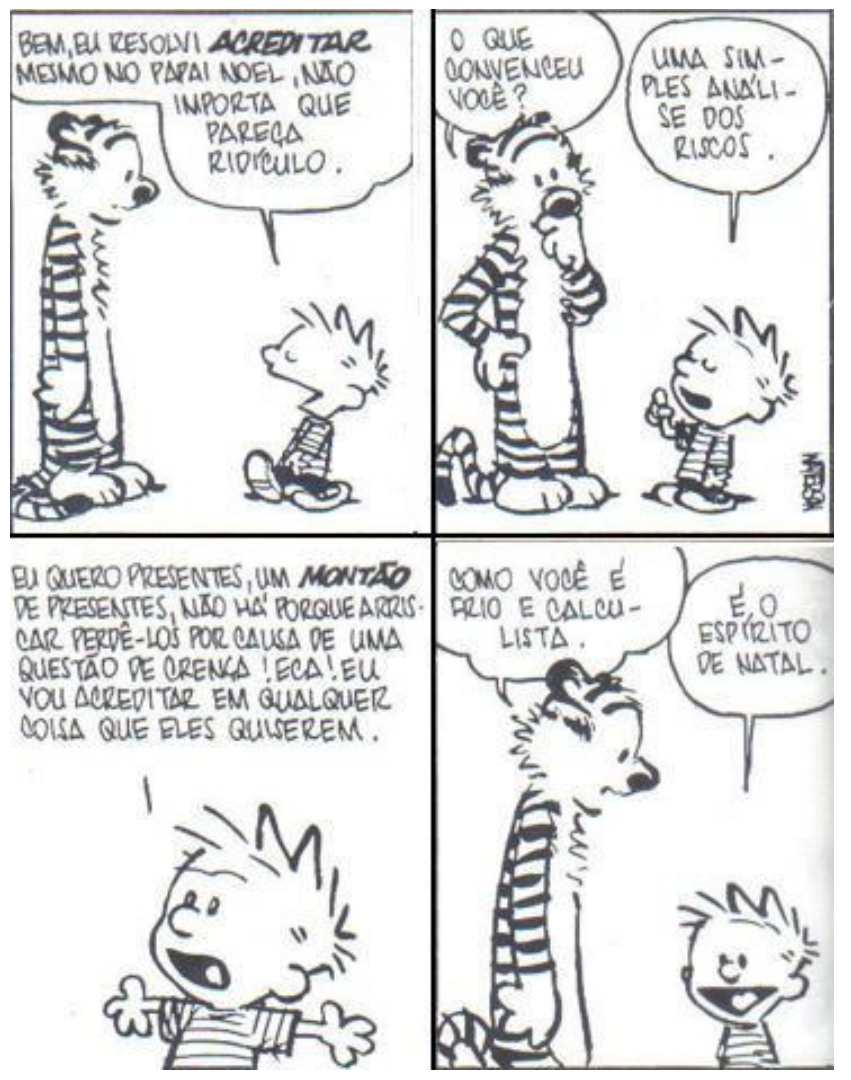

Fonte: extraído de https://coachingsp.wordpress.com/tag/quadrinhos/

As outras duas traduções (fig. 4 e fig. 5) mantêm o formato de tira:

Figura 4 - Tira de Calvin e Haroldo em português ${ }^{15}$ em formato de tira
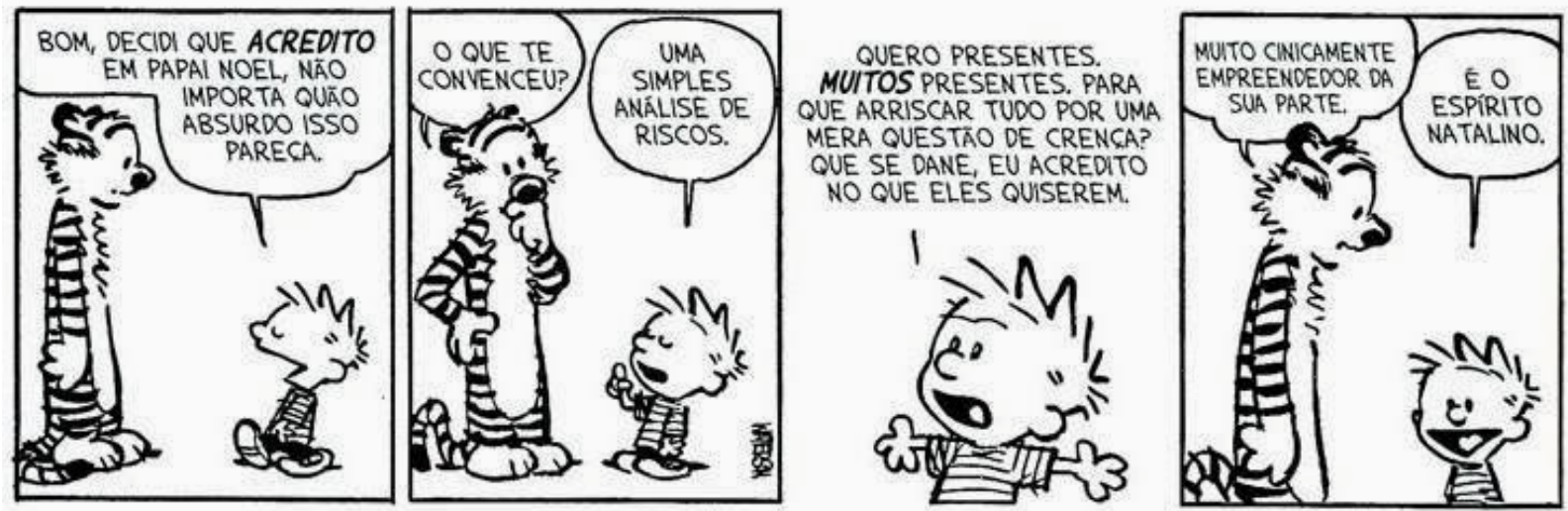

\footnotetext{
${ }^{14} \mathrm{~A}$ tira que ilustra este artigo foi obtida no site https://coachingsp.wordpress.com/tag/quadrinhos/em 17 de abril de 2017. Ela está, em formato original de tira na coletânea 'Yukon, hei! Uma coletânea de Calvin e Haroldo', publicada pela Cedibra Editora Brasileira Ltda, em 1989. As letras são de Renilton e a tradução de Cleide Tavares e J. Scott.

${ }^{15}$ A tira foi obtida no site: http://www.conversacult.com.br/2013/12/resenha-papai-noel-uma-biografiade.html. Está na coletânea 'Yukon, ho!' publicada pela editora Conrad, em 2008. O tradutor é André
} 
REVISTA X, Curitiba, volume 14, n.3,p. 33-49, 2019.

Fonte: extraído de http://www.conversacult.com.br/2013/12/resenha-papai-noel-uma-biografiade.html.

Figura 5 - Tira de Calvin e Haroldo em português ${ }^{16}$ publicada no jornal O Estado de São Paulo

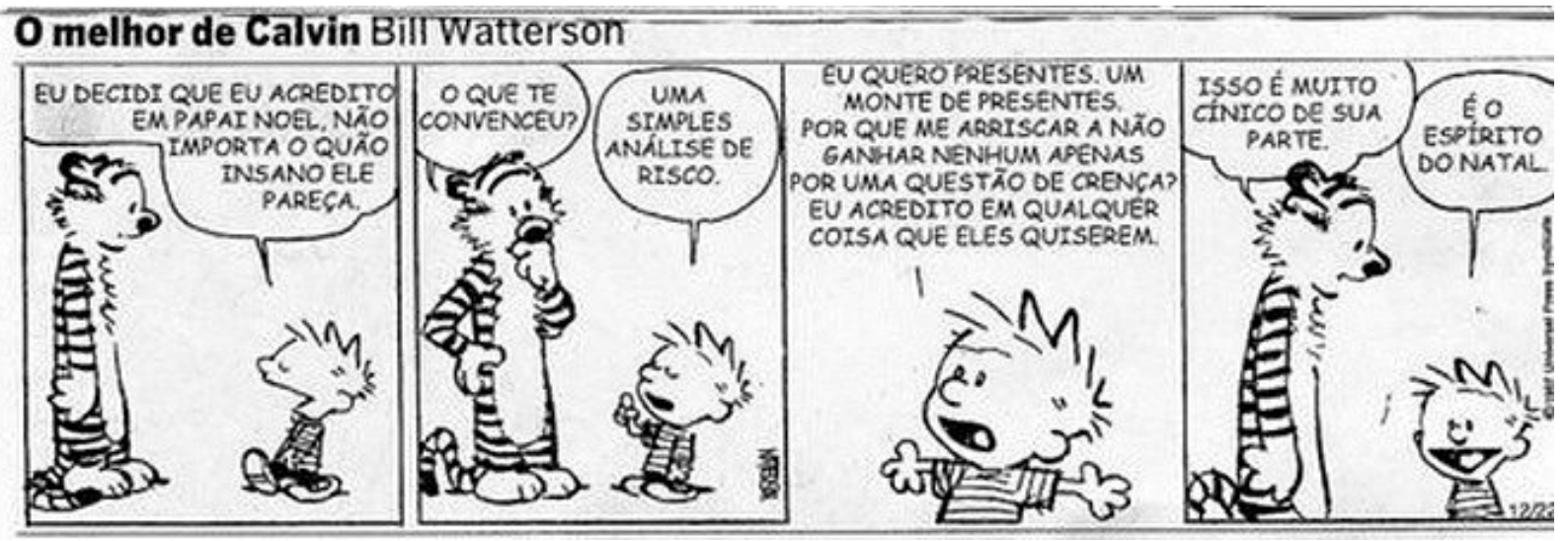

Fonte: extraído de https://cronicasurbanas.wordpress.com/tag/calvin/.

O tipo de letra e a distribuição das palavras nos balões de diálogo nas figuras 4 e 5, apesar de manterem a letra maiúscula, são bastante diferentes da tira original.

Os desenhos não sofreram alterações ou adaptações em nenhuma das traduções. As tiras foram criadas e publicadas em uma época em que as leis de direitos autorais e os sindicatos impediam este tipo de prática ${ }^{17}$. O próprio Bill Watterson foi bastante exigente e consciente em relação às imposições de editores e jornais no seu processo criativo e não aceitou intervenções. Ele também não se dobrou à vontade da indústria midiática no que se refere ao licenciamento de produtos a partir de seus personagens ${ }^{18}$.

Quanto aos aspectos linguísticos e ao produto das traduções ao espanhol e ao português, pode-se notar que há diferenças entre as versões ${ }^{19}$ da tira disponíveis neste artigo.

A seguir, está reproduzida a fala de Calvin no primeiro balão da tira:

Conti e as letras de Lilian Matsunaga. Diferentemente da versão da editora Cenibra, o título do álbum é o mesmo do original em inglês e não há o nome dos personagens na capa.

${ }^{16}$ A tira foi obtida no site: https://cronicasurbanas.wordpress.com/tag/calvin/. Supõe-se que é a tira publicada no jornal O Estado de São Paulo pela presença da identificação 'O Melhor de Calvin'.

${ }^{17}$ Assis (2016) comenta que houve adaptações nos desenhos da tira Peanuts (Snoopy) publicadas na revista alemã Stern para adequar os desenhos norte-americanos ao universo infantil alemão.

18 Informações do blog: http://depositodocalvin.blogspot.com/2009/04/biografia-de-bill-watterson.html . Consulta em: 20 fev. 2016.

${ }^{19}$ Inicialmente, pretendíamos usar uma tira em cada idioma, porém, ao descobrirmos mais de uma tradução ao português da mesma tira com tantas diferenças entre elas, decidimos usar as 3 tiras em português, além de 1 em espanhol. 
REVISTA X, Curitiba, volume 14, n.3,p. 33-49, 2019.

Fig. 1.Well, I've decided I do believe in Santa Claus, no matter how preposterous he sounds.

Fig. 2. Bueno, he decidido creer en Papá Noel, por muy idiota que suene.

Fig. 3. Bem, eu resolvi acreditar mesmo no Papai Noel, não importa que pareça ridículo.

Fig. 4. Bom, decidi que acredito em Papai Noel, não importa quão absurdo isso pareça.

Fig. 5. Eu decidi que acredito em Papai Noel, não importa o quão insano ele pareça.

É importante lembrar que uma das características das HQs é que procuram representar na escrita vários aspectos da oralidade ${ }^{20}$. A função do balão é colocar a fala "na boca dos personagens" (como o discurso direto em textos literários). Marcas como expressões, hesitações, ênfase, sotaques, etc. estão presentes nos diálogos de HQs e os tradutores precisam fazer adaptações para não perdê-las no texto meta.

Apesar de ser algo encontrado em outras traduções de HQs, a omissão da interjeição que inicia a fala do personagem na tira analisada (fig. 1) só foi feita em uma das traduções ao português (fig. 5). Entretanto, outra marca de oralidade, a ênfase (marcada com negrito), foi mantida somente em duas das versões. No caso das traduções ao português, justamente aquela tradução que omite a interjeição é a que não manteve o negrito, ou seja, a tradução ao português que está na fig. 5 é aquela que mais se distancia do texto fonte quanto ao registro oral.

Nenhum dos tradutores fez tradução literal. Algo impossível neste caso em razão das características de cada uma das línguas envolvidas (número de palavras, ordem sintática, categorias lexicais). Assim, a modalidade utilizada em parte da tradução da tira foi a transposição em que se fazem rearranjos morfossintáticos, desdobramentos lexicais, mudança na ordem das palavras e escolhas dentre as opções possíveis na própria língua meta:

Fig. 1. What convinced you?

Fig. 2. ¿Qué te ha convencido?

Fig. 3. O que convenceu você?

Fig. 4. O que te convenceu?

Fig. 5. O que te convenceu?
A simple risk analysis.

Un simple análisis de riesgo.

Uma simples análise dos riscos.

Uma simples análise de riscos.

Uma simples análise de risco.

No fragmento anterior, há transposições obrigatórias, como a mudança de ordem de palavras na resposta dada por Calvin e a introdução de preposição ('a simple

\footnotetext{
${ }^{20}$ Ramos (2006) demonstra como fala, escrita e oralidade podem ser abordadas como conteúdo de aula ao sugerir o uso de HQs em aulas de língua portuguesa.
} 
REVISTA X, Curitiba, volume 14, n.3,p. 33-49, 2019.

risk analysis / un simple análisis de riegos') quanto transposições facultativas, como a tradução de 'risk analysis' para 'dos riscos/ de riscos / de risco', em que há variação na preposição com ou sem artigo definido plural e na marca de plural no substantivo.

Ao comparar a primeira vinheta de cada figura, é possível identificar características do inglês como o uso do tempo verbal presente perfect, a estrutura da oração relativa e escolhas lexicais. Entretanto, uma característica sintática foi escolhida para ser explorada na análise desta vinheta: trata-se da presença ou não do pronome tônico em função de sujeito oracional e a identificação de seu referente no discurso. Notou-se que, neste caso, a tradução do segmento textual gerou considerável deslocamento tanto estrutural quanto semântico, afastando o texto fonte do texto meta (tanto em espanhol quanto em português). Em alguns casos interpreta-se que a modalidade de tradução foi a modulação e, em outros, o acréscimo. Porém, não se pode deixar de notar que houve erro de tradução também, visto que houve considerável modificação no significado denotativo-referencial.

Entre os estudos que abordam o pronome pessoal e o sujeito oracional estão os desenvolvidos pelo Programa de Princípios e Parâmetros, dentro dos estudos gerativistas, nos anos $80^{21}$. O Parâmetro do Sujeito Nulo ${ }^{22}$ indica que algumas línguas são pro-drop (pronoun-dropping), ou seja, permitem anáfora zero ou [Ø], um fenômeno no qual certa classe de pronomes pode ser omitida quando possa, de alguma forma, ser recuperada pragmaticamente.

No caso do inglês, do espanhol e do português, temos línguas que são bastante diferentes. De acordo com Kato (1999, apud XAVIER, 2009), o inglês não é uma língua pro-drop; ao contrário, é uma língua de morfologia de concordância verbal pobre em que a presença do pronome sujeito é obrigatória. O espanhol, por outro lado, está classificado no grupo de línguas pro-drop, em que a presença do pronome pessoal com função de sujeito é rara. O português é considerado uma língua semi pro-drop ou prodrop parcial; entretanto, mudanças ocorridas na evolução histórica da língua estão levando-a a ser cada vez mais caracterizada pelo preenchimento do sujeito.

\footnotetext{
${ }^{21}$ Sugere-se a leitura de:

RAPOSO, E.P. A teoria da gramática. A faculdade da linguagem. Lisboa: Caminho, 1991.

Além da obra de Noam Chomsky, em especial:

CHOMSKY, N. Lectures on Government and Binding. Dordrecht: Foris, 1981.

CHOMSKY, N. Knowledge of language: its nature, origin and use. New York: Praege, 1986.

${ }^{22}$ Para mais detalhes, sugere-se a leitura de: KATO, M. Questões atuais da aquisição de L1 na perspectiva da teoria de princípios e parâmetros. Cadernos de Estudos Lingüísticos, Campinas, São Paulo: n. 36, p. 11-16, 1999.
} 
REVISTA X, Curitiba, volume 14, n.3,p. 33-49, 2019.

Nos exemplos da primeira vinheta da tira, verifica-se claramente a diferença entre o inglês, com todos os pronomes sujeito explícitos, e o espanhol, com elipse em todos os lugares argumentais de sujeito oracional.

Fig. 1.Well, I've decided I do believe in Santa Claus, ${ }_{i}$ no matter how preposterous $\underline{h e}_{i}$ sounds.

Fig. 2. Bueno, [Ø] he decidido creer en Papá Noel, por muy idiota que [Ø] suene.

A característica sintática do inglês permite identificar claramente os referentes dos pronomes. No caso do referente do pronome de $3^{\text {a }}$ pessoa, não há dúvidas que he $=$ Santa Claus.

Entretanto, no caso do espanhol, o referente da [Ø] só está claro no primeiro verbo ([yo] he decidido), mas não no outro ([Ø] suene). No caso da segunda [Ø], podese interpretar que o referente é: um Sintagma Oracional (SO) [crer en Papá Noel] ou, como no inglês, o Sintagma Nominal (SN) [Papá Noel]. Assim, neste caso, houve um acréscimo, pois a interpretação de que o referente da [Ø] é um SO não estava previsto no texto fonte. A ambiguidade gerada na tira em espanhol, não chega a prejudica-la, ao contrário, parece enriquecê-la.

Nas traduções ao português, há três realizações diferentes para o sujeito do verbo 'parecer': $[\varnothing]$, demonstrativo neutro ‘isso’ e pronome pessoal tônico ‘ele'.

Fig. 3. Bem, eu resolvi acreditar mesmo no Papai Noel, não importa que [Ø] pareça ridículo.

Fig. 4. Bom, decidi que acredito em Papai Noel, não importa quão absurdo isso pareça.

Fig. 5. Eu decidi que acredito em Papai Noel, não importa o quão insano ele pareça.

Na fig. 3, a [Ø] é interpretada como o SO (acreditar mesmo no Papai Noel). Outra possibilidade é de que a [Ø] tenha como referente 'eu' (não importa que [eu] pareça ridículo), embora esta interpretação não seja aquela dada primeiramente por falantes de português brasileiro. Interpretar a [Ø] como sendo 'Papai Noel' não foi uma possibilidade dada por falantes consultados informalmente, porém, é linguisticamente é uma possibilidade.

Na fig. 4, 'isso' é interpretado como o SO (acredito em Papai Noel).

Na fig. 5, 'ele' só pode ser interpretado como o SN (Papai Noel). É a tradução que se aproxima mais do texto fonte quanto à interpretação do sujeito da última oração, trata-se de uma tradução literal da palavra he do inglês.

Ao contrário da tradução ao espanhol, a tradução ao português gerou duas possibilidades (fig. 3 e fig. 4) diferentes do texto fonte e uma (fig. 5) que manteve seu 
sentido original. As traduções da fig. 3 e da fig. 4 seriam consideradas erros de tradução.

Entretanto, para o falante brasileiro, as duas outras traduções seriam as formas mais aceitáveis, apesar de mais distantes do texto fonte. Entre um grupo de falantes de português com nível superior de escolaridade ${ }^{23}$ que foi informalmente consultado, percebeu-se que há equilíbrio entre as duas formas ([Ø] e 'isso') em que se pode interpretar que o referentes é o SO (acreditar em Papai Noel) em relação à terceira ('ele'= Papai Noel). Ou seja, poderíamos apresentar como hipótese que os usos mais distantes do texto fonte poderiam ser considerados como correção, uma melhoria feita a uma inadequação detectada no original, e não simplesmente erro tradutório.

\section{CONSIDERAÇÕES FINAIS}

Neste artigo, procurou-se estudar as peculiaridades da tradução de HQs tomando como base as modalidades da tradução desenvolvidas por Aubert (1998) e as adaptações feitas por Silva (2015). O objeto de análise foi uma tira de Calvin e Haroldo. Buscou-se considerar as características próprias do gênero HQ e analisar as características das línguas envolvidas (inglês, espanhol e português), em especial a realização do sujeito oracional e a interpretação da anáfora. As características sintáticas das línguas quanto ao item analisado geraram traduções cujos significados se distanciaram do texto fonte sem, contudo, prejudicar o humor da tira.

Apesar de que as modalidades de tradução propostas por Aubert (1998) pretederem ser objetivas quando à marcação de distância entre o texto original e o texto meta, notou-se, na análise da tira de Calvin e Haroldo, que há características linguísticas e culturais que fazem com que determinadas traduções tenham a preferência dos leitores de determinada língua, no caso, do português, mesmo que estejam mais distantes do texto original.

Sabe-se que as HQs são consideradas como materiais importantes em aulas de diferentes disciplinas. No caso das línguas estrangeiras, são excelente input para os estudantes e, em atividades de tradução, possibilitam a percepção das peculiaridades linguísticas do texto fonte e do texto meta que não seriam tão evidentes no estudo isolado de uma língua. Conclui-se, assim, que as HQs são um material rico para os

\footnotetext{
${ }^{23}$ Em pesquisa informal feita com 8 graduados em letras, alguns deles estudantes universitários de pósgraduação em linguística, foi solicitado que traduzissem o primeiro balão da tira. Somente metade (4) traduziu ' $h e$ ' como 'ele'. Os demais traduziram como 'isso' (3) ou [Ø] (1).
} 
REVISTA X, Curitiba, volume 14, n.3,p. 33-49, 2019.

estudos tradutórios e pode ser objeto de pesquisa a ser explorado a partir de diferentes perspectivas.

\section{REFERÊNCIAS}

ASSIS, E. G. Especificidades da tradução de histórias em quadrinhos: abordagem inicial TradTerm, São Paulo, v. 27, setembro 2016, p.15-37. Disponível em: http://www.academia.edu/30284544/Especificidades_da_tradu\%C3\%A7\%C3\%A3o_de_hist\%C 3\%B3rias_em_quadrinhos_abordagem_inicial_Comics_translation_particularities_Initial_appro ach. Acesso em: 8 abr. 2017.

AUBERT, F. H. Modalidades de tradução: teoria e resultados. TradTerm, 5(1) 1osem 1998, p. 99-125 37.

EISNER, W. Quadrinhos e arte sequencial. Trad. de Luís Carlos Borges. São Paulo: Martins Fontes, 2001.

Disponível em: $\quad$ https://pt.slideshare.net/Recursosparaquadrinistas/will-eisnerquadrinhos-e-arte-sequencial-34776891. Acesso em: 08 abr. de 2017.

MENDONÇA, M. R. S. Um gênero quadro a quadro: a história em quadrinhos. In: DIONÍSIO, A. P.et al. Gêneros textuais \& ensino. São Paulo: Parábola, 2010, p. 209224.

RAMOS, P. Os quadrinhos em aulas de língua portuguesa. In: BARBOSA, A. et al. Como usar as histórias em quadrinhos na sala de aula. São Paulo: Contexto, 2006, p. $65-85$.

SILVA, B. Z. As tiras de Mafalda no Brasil: tradução e tradutores. Dissertação (Mestrado em Letras). São Paulo, Faculdade de Filosofia, Letras e Ciências Humanas, Universidade de São Paulo, 2015.

SILVA, M. I. M. Tradução da banda desenhada: o caso de Calvin \& Hobbes. Dissertação (Mestrado em Tradução) Lisboa, Faculdade de Ciências Humanas e Sociais, Universidade de Nova Lisboa, 2013.

VERGUEIRO, W. O uso das HQs no ensino. In: BARBOSA, A. et al. Como usar as histórias em quadrinhos na sala de aula. São Paulo: Contexto, 2006, p. 07-30.

WATTERSON, B. Yukon, ho! A Calvin and Hobbes Collection. Kansas City: Andrews McMeel Publishing, 1989.

Yukon, hei! Uma coletânea de Calvin e Haroldo. Tradução de Cleide Tavares e J. Scott. Cedibra Editora Brasileira Ltda, 1989, p. 100.

Yukon, ho! São Paulo: Conrad, 2008.

$$
\text { Calvin \& Hobbes. Disponível }
$$

em:

https://www.buzzfeed.com/ariannarebolini/christmas-lessons-from-calvin-andhobbes?utm_term=.hegBBrmrE2\#.ptWOOMIMey. .Acesso em: 14 abr. 2017. 
REVISTA X, Curitiba, volume 14, n.3,p. 33-49, 2019.

Calvin

e Haroldo.

Disponível

em :

https://coachingsp.wordpress.com/tag/quadrinhos/ . Acesso em 17 abr. 2017.

Calvin $\quad y \quad$ Hobbes. Disponível

http://ateismoparacristianos.blogspot.com/search?q=calvin. Acesso em: 20 abr. 2017

Calvin Haroldo. Disponível em:

http://www.conversacult.com.br/2013/12/resenha-papai-noel-uma-biografia-de.html.

Acesso em: 02 mai 2017.

O melhor de Calvin. Disponível em:

https://cronicasurbanas.wordpress.com/tag/calvin/. Acesso em: 03 mai 2017.

XAVIER, G. R. O parâmetro do sujeito nulo na aquisição do português como L2. Estudos da Lingua(gem). Vitoria da Conquista, v.7, n.2, 2009, p. 133-162. Disponível em:

http://www.estudosdalinguagem.org/index.php/estudosdalinguagem/article/viewFile/13 0/237.Acesso em: 23 abr. 2017. 